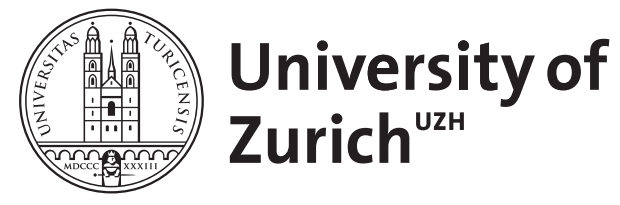
Archive

University of Zurich

Main Library

Strickhofstrasse 39

CH-8057 Zurich

www.zora.uzh.ch

Year: 2009

Rules and self-rules: effects of variation upon behavioral sensitivity to change

Baumann, A A ; Abreu-Rodrigues, Josele ; Da Silva Souza, Alessandra

DOI: https://doi.org/10.1007/BF03395685

Posted at the Zurich Open Repository and Archive, University of Zurich

ZORA URL: https://doi.org/10.5167/uzh-40461

Journal Article

Originally published at:

Baumann, A A; Abreu-Rodrigues, Josele; Da Silva Souza, Alessandra (2009). Rules and self-rules: effects of variation upon behavioral sensitivity to change. Psychological Record, 59(4):641-670.

DOI: https://doi.org/10.1007/BF03395685 
The Psychological Record, 2009, 59, 641-670

\title{
RULES AND SELF-RULES: EFFECTS OF VARIATION UPON BEHAVIORAL SENSITIVITY TO CHANGE
}

\author{
Ana A. Baumann \\ Washington University in St. Louis \\ Josele Abreu-Rodrigues and Alessandra da Silva Souza \\ Universidade de Brasília
}

\begin{abstract}
Four experiments compared the effects of self-rules and rules, and varied and specific schedules of reinforcement. Participants were first exposed to either several schedules (varied groups) or to one schedule (specific groups) and either were asked to generate rules (self-rule groups), were provided rules (rule groups), or were not asked nor provided rules (control groups). When exposed to FI, sensitivity was greater for the varied than for the specific self-rules and rules groups, regardless of reinforcement rate. Control groups showed intermediate sensitivity levels. When nondifferentiated response rates were obtained, sensitivity for the varied groups was similar to that observed for the specific groups. These results suggest that varied rules promote greater sensitivity than do specific ones as long as variable behavior patterns are obtained.
\end{abstract}

Keywords: verbal behavior, rule-governed behavior, contingency control, behavior sensitivity to change, schedules of reinforcement, behavioral sensitivity, self-rules, rules, variation, humans

Verbal statements describing contingencies of reinforcement or punishment, such as instructions, rules, advice, or commands, have been most widely denominated as "rules" (Skinner, 1969). Rules have important effects on behavior. Under some circumstances, rules may facilitate the development of contingency control. For example, in the presence of rules, contingencyappropriated behavior tends to be acquired faster (e.g., Ayllon \& Azrin, 1964). This effect has been reported when contingencies are complex (Baron,

Experiment 1 was derived from a master thesis submitted by the first author to the Universidade de Brasília. Portions of these data were presented at the 29th Annual Convention of the Association for Behavior Analysis (San Francisco, 2003), the XII Encontro Anual da Associação Brasileira de Psicoterapia e Medicina Comportamental (Londrina, 2003), and the 31st Annual Convention of the Association for Behavior Analysis (Chicago, 2005). The authors thank Fernando Rocha for developing the computer software and Junnia Moreira for collecting the data for Experiment 4 . We also thank Cristiano Santos, Phillip Chase, and Tim Hackenberg for many invaluable comments and suggestions on the manuscript.

Correspondence concerning this article may be sent to Josele Abreu-Rodrigues at the Departamento de Processos Psicológicos Básicos, Instituto de Psicologia, Universidade de Brasília, Campus Universitário Darcy Ribeiro, Brasília, Distrito Federal, Brasil, 70.910-900. E-mail: abreu@ unb.br 
Kaufman, \& Stauber, 1969; Takahashi \& Shimakura, 1998), imprecise (Cerutti, 1991), or aversive (Galizio, 1979). Under other circumstances, however, rules may impair control by the prevailing contingencies. Accordingly, studies have shown that when contingencies change, such that rules no longer correspond to the current contingency, rule-controlled behavior may remain unaltered (e.g., Kaufman, Baron, \& Kopp, 1966; Paracampo, Souza, Matos, \& Albuquerque, 2001; Shimoff, Catania, \& Matthews, 1981). When behavior, verbally mediated or not, does not change with changing contingencies, it can be said that behavioral insensitivity was observed. If, on the other hand, behavior changes when contingencies change, it is said that behavior was sensitive to the change in contingencies (Madden, Chase, \& Joyce, 1998).

Because much of human behavior is taught through rules, and behavioral insensitivity may not always be adaptive, many studies from human operant laboratories have focused on identifying the variables of rule-controlled behavior that increase behavior sensitivity to change. Sensitivity to change is more likely to occur when (a) the prevailing contingencies do not support rule-governed behavior (e.g., Galizio, 1979; Newman, Hemmes, Buffington, \& Andreopoulos, 1994), (b) rules do not fully describe task performance and/or contingencies (e.g., Danforth, Chase, Dolan, \& Joyce, 1990; Raia, Shillingford, Miller, \& Baier, 2000), (c) the new task is of low complexity (Albuquerque \& Ferreira, 2001), (d) individuals have a history of extinction or punishment for following rules (e.g., Hackenberg \& Joker, 1994; Martinez-Sanchez \& RibesIñesta, 1996), and (e) competitive social reinforcement for rule following (i.e., a pliance contingency) is not present (e.g., Barrett, Deitz, Gaydos, \& Quinn, 1987; Hayes, Brownstein, Zettle, Rosenfarb, \& Korn, 1986; Navarick, 2004; Otto, Torgrud, \& Holborn, 1999).

Another factor that promotes sensitivity of rule-controlled behavior is a history with varied rules and schedules. In a study conducted by LeFrancois, Chase, and Joyce (1988), undergraduate students were assigned to one of three groups: variety rule, specific rule, and specific control. During the training phase, the variety rule group was exposed to three types of schedules of reinforcement: variable interval (VI), fixed time (FT), and fixed ratio (FR). Half of the participants were also exposed to a differential reinforcement of low rates (DRL) schedule. The specific rule and specific control groups were exposed to only one type of schedule: variable ratio (VR) or VI. Accurate schedule descriptions (hereafter called rules) were presented to the participants in the variety rule and specific rule groups before each reinforcement schedule. Participants in the specific control groups did not receive rules. During the testing phase, in which no rules were given, a fixed-interval (FI) schedule was in effect. In the training phase, low, moderate, and high response rates were observed for the participants in the variety rule group. High response rates tended to be presented by participants in the specific rule and specific control groups exposed to the VR schedule, whereas low rates were observed for participants in the specific rule group exposed to the VI schedule. In the testing phase, response rates decreased with the introduction of the FI schedule for the participants in the variety group, while response rates remained unaltered for participants in the specific rule and specific control groups. The results of that study indicated that greater sensitivity to change was observed when participants were exposed to a diverse experimental history that comprised exposure to varied rules and varied schedules, which produced response-rate differentiation (see also Joyce \& Chase, 1990; Wulfert, Greenway, Farkas, Hayes, \& Dougher, 1994). 
The LeFrancois et al. (1988) study, however, did not include a variety control group, that is, a group exposed to varied schedules in the absence of rules. The absence of such a control raises the question of which aspect of the variety training promoted behavioral sensitivity. There were at least three possible controlling variables: varied rules, varied schedules, and differentiated response rates. The main goal of the present study was to evaluate the contribution of those variables on behavioral sensitivity. To isolate the effects of varied schedules from varied rules, participants in the present study were exposed to several schedules, but only some of them received rules. Also, to assess the effects of response-rate differentiation, two varied trainings were compared: one with schedules that produced high, intermediate, and low response rates and another with schedules that generated high and undifferentiated response rates.

Studies of rule-controlled behavior usually assess the effects of rules that are provided by the experimenter. However, rules can also be generated by the participants themselves (Cabello, Luciano, Gomez, \& Barnes-Holmes, 2004; Matthews, Catania, \& Shimoff, 1985; Rosenfarb, Newland, Brannon, \& Howey, 1992; Torgrud \& Holborn, 1990). For example, in the study conducted by Rosenfarb et al., college students were exposed to a multiple FR DRL schedule during the training phase and allocated into three groups: selfgenerated rule, yoked rule, and no rule (control). Participants in the selfgenerated rule group were asked to describe the best way to earn points. Their descriptions, regardless of their accuracy, were given to participants of the yoked rule group. Participants in the no rule group did not generate rules, nor did they receive rules. In the testing phase, all participants were exposed to extinction. By the end of training, most participants in the selfgenerated rule group provided accurate descriptions of the FR and DRL schedules. Moreover, differentiated response rates were acquired faster, and extinguished slower, for participants in the self-generated rule and yoked rule groups than for those in the no rule group. These data indicate that selfgenerated rules, like rules from others, may facilitate behavioral acquisition but delay extinction of behavior, thus producing behavioral insensitivity to contingency changes.

In the Rosenfarb et al. (1992) study, a specific self-rule produced effects similar to those observed with a specific rule, and in the LeFrancois et al. (1988) study, varied rules engendered greater behavioral sensitivity than did specific rules. If both findings are taken into account, it seems feasible to suggest that varied self-rules would also produce more sensitive behavior than would specific self-rules. To investigate this suggestion was another goal of the present study.

The general procedure used in the present series of experiments was a synthesis of that used by LeFrancois et al. (1988) and Rosenfarb et al. (1992). College students were exposed to training and testing phases. During the training phase, participants were exposed to three types of schedules (varied groups) or to only one type of schedule (specific groups). Each of the varied and specific groups included three subgroups: self-rule, rule, and control. Participants in the self-rule groups were asked to provide rules. Participants in the rule groups received either those rules or rules generated by the experimenter. Participants in the control groups neither were asked to provide nor received any rules. During the testing phase, all groups were exposed to an FI schedule, and there were no explicit rules. 


\section{EXPERIMENT 1}

Experiment 1 compared the effects of varied and specific self-rules and rules. In this experiment, each participant in the varied and specific self-rule groups generated rules by answering a multiple-choice question. Those rules were then given to a yoked participant in the respective varied and specific rule groups. Two control groups were included in an attempt to disentangle the potential effects of schedules and rules upon behavioral sensitivity. Participants in one control group were exposed to varied schedules (varied control group), and those in the other control group were exposed to a specific schedule (specific control group). Participants in the control groups were not required to generate rules or given yoked rules.

The design employed in this study permitted us to test several predictions. First, if variation in schedules (and rules) is critical to behavioral sensitivity, then participants in the varied groups should present greater behavioral change than participants in the specific groups when exposed to the FI schedule. Second, if self-rules and rules are functionally similar, then participants in the self-rule and rule groups should present comparable levels of behavioral sensitivity to the FI schedule. Third, if the critical variable in promoting behavioral sensitivity in the LeFrancois et al. (1988) study was the exposure to varied rules, then participants in the self-rule and rule groups should present greater behavioral change with the change to the FI schedule than participants in the control groups.

\section{Method}

\section{Participants}

Twenty-seven students (21 women, 6 men) from the Universidade de Brasília and the Centro Universitário de Brasília (Brasilia, Brazil) participated in this experiment. Their ages ranged from 18 to 26 years, and none had experience with operant conditioning experiments. Participants were asked to read and sign an informed consent. All participants earned extra credit in introductory psychology classes. Points earned by each participant were converted into chances to win a cash prize (approximately \$60 US) at the conclusion of the study.

\section{Setting and Apparatus}

The study was conducted in a room $(2.30 \mathrm{~m} \times 1.82 \mathrm{~m})$ with partial acoustic insulation. The room contained a table, a chair, an IBM-compatible personal computer, and a printer. The experiment was controlled by Visual Basic $6^{\circledR}$ software that programmed stimulus presentations and registered keyboard responses.

\section{Procedure}

There were two experimental phases: training and testing. Participants were randomly assigned to one of six groups: varied self-rule, varied rule, varied control, specific self-rule, specific rule, and specific control (see Table 1). 
Table 1

Experimental Conditions for the Varied and Specific Groups in Experiments 1, 2,3 , and 4

\begin{tabular}{|c|c|c|c|c|c|c|}
\hline Phases & $\begin{array}{l}\text { Varied } \\
\text { groups }\end{array}$ & $\begin{array}{l}\text { Verbal } \\
\text { stimuli }\end{array}$ & $\begin{array}{c}\text { Varied } \\
\text { schedules }\end{array}$ & $\begin{array}{l}\text { Specific } \\
\text { groups }\end{array}$ & $\begin{array}{l}\text { Verbal } \\
\text { stimuli }\end{array}$ & $\begin{array}{c}\text { Specific } \\
\text { schedules }\end{array}$ \\
\hline \multicolumn{7}{|c|}{ Experiment 1 (multiple choice) } \\
\hline \multirow{3}{*}{ Training } & VSR & Self-rules & \multirow{3}{*}{$\begin{array}{l}\text { VI } 5 \text { s; VI } 15 \text { s; } \\
\text { FT } 5 \text { s; FT } 15 \text { s; } \\
\text { FR 5; FR } 15\end{array}$} & SSR & Self-rules & \multirow{3}{*}{ FR 5; FR 15} \\
\hline & VR & Rules & & SR & Rules & \\
\hline & VC & No rules & & SC & No rules & \\
\hline \multirow{3}{*}{$\begin{array}{c}\text { Brief } \\
\text { training }\end{array}$} & VSR & Self-rules & \multirow{3}{*}{$\begin{array}{l}\text { VI } 5 \text { or } 15 \mathrm{~s} \\
\text { FT } 5 \text { or } 15 \mathrm{~s} \\
\text { FR } 5 \text { or } 15\end{array}$} & SSR & Self-rules & \multirow{3}{*}{ FR 5 or 15} \\
\hline & VR & Rules & & SR & Rules & \\
\hline & VC & No rules & & SC & No rules & \\
\hline Testing & All & No rules & $\mathrm{FI} 15 \mathrm{~s}$ & All & No rules & $\mathrm{FI} 15 \mathrm{~s}$ \\
\hline \multicolumn{7}{|c|}{ Experiment 2 (open-ended questions) } \\
\hline Training & VSR & Self-rules & VI $5 \mathrm{~s} ;$ VI $15 \mathrm{~s}$ & SSR & Self-rules & \multirow{2}{*}{ FR 5; FR 15} \\
\hline талтиту & VR & Rules & FR 5; FR 15 & SR & Rules & \\
\hline \multirow{2}{*}{$\begin{array}{c}\text { Brief } \\
\text { training }\end{array}$} & & & $\begin{array}{l}\text { VI } 5 \text { or } 15 \mathrm{~s} \\
\text { FT } 5 \text { or } 15 \mathrm{~s}\end{array}$ & SSR & & \multirow{2}{*}{ FR 5 or 15} \\
\hline & VR & Rules & FR 5 or 15 & SR & Rules & \\
\hline Testing & All & No rules & $\mathrm{FI} 15 \mathrm{~s}$ & All & No rules & $\mathrm{FI} 15 \mathrm{~s}$ \\
\hline \multicolumn{7}{|c|}{ Experiment 3 (undifferentiated response rates) } \\
\hline \multirow{3}{*}{ Training } & VSR & Self-rules & \multirow{3}{*}{$\begin{array}{l}\text { RR 5; RR 15; } \\
\text { VR 5; VR 15; } \\
\text { FR 5; FR 15 }\end{array}$} & & & \\
\hline & VR & Rules & & & & \\
\hline & VC & No rules & & & & \\
\hline \multirow{3}{*}{$\begin{array}{c}\text { Brief } \\
\text { training }\end{array}$} & VSR & Self-rules & \multirow{3}{*}{$\begin{array}{l}\text { RR } 5 \text { or } 15 ; \\
\text { VR } 5 \text { or } 15 ; \\
\text { FR } 5 \text { or FR } 15\end{array}$} & & & \\
\hline & VR & Rules & & & & \\
\hline & VC & No rules & & & & \\
\hline Testing & All & No rules & $\mathrm{FI} 15 \mathrm{~s}$ & & & \\
\hline \multicolumn{7}{|c|}{ Experiment 4 (equated number of FR reinforcers) } \\
\hline \multirow{3}{*}{ Training } & & & & SSR & Self-rules & \multirow{3}{*}{ FR 5; FR 15} \\
\hline & & & & SR & Rules & \\
\hline & & & & SC & No rules & \\
\hline \multirow{3}{*}{$\begin{array}{c}\text { Brief } \\
\text { training }\end{array}$} & & & & SSR & Self-rules & \multirow{3}{*}{ FR 5 or 15} \\
\hline & & & & $\mathrm{SR}$ & Rules & \\
\hline & & & & SC & No rules & \\
\hline Testing & & & & All & No rules & $\mathrm{FI} 15 \mathrm{~s}$ \\
\hline
\end{tabular}




\section{Training Phase}

Varied groups. All participants in these groups received the following instruction at the beginning of the training phase. The instruction was written in Portuguese and translates to English as follows:

(1) Thank you for participating in this study. We are interested in investigating certain aspects of the learning process that are similar to all people. During the session you will be alone in this room.

(2) The session will start when a pyramid is shown on the screen. Your task is to move the colored square from the top to the bottom of this pyramid. To do that, press either the blue or the yellow key on the keyboard. When the colored square reaches the bottom of the pyramid, a beep will sound indicating that you won a point. To register your point on the counter, located at the top right of the screen, press the space bar.

(3) Try to earn as many points as possible. Points earned will be exchanged for coupons that will give you the chance to win a cash prize at the end of this study. The more points you win, the more coupons you will receive, and the greater your chances will be to win the cash prize.

(4) Do not ask questions of the experimenter. You will be informed when the session is over. When you are ready to start, press the space bar.

At the beginning of the session, a pyramid with nine horizontal rows and a colored square (cursor) at the top was shown on the screen (see Figure 1). The experimental task consisted of moving the cursor from the top to the bottom of the pyramid. Points were awarded when the cursor reached the bottom of the pyramid (i.e., after eight cursor movements). To move the cursor to the row immediately below, participants had to press keys "F" and "J," which were covered with blue and yellow papers, respectively. Presses on the blue key moved the cursor to the right and presses on the yellow key moved the cursor to the left. To prevent participants from pressing other keys, the rest of the keyboard was covered with white paper, so that only keys "F" and "J" and the space bar were available.

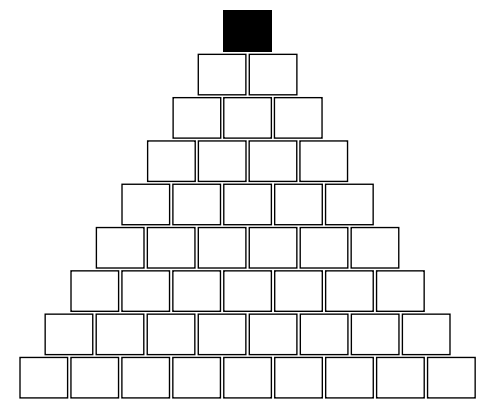

Figure 1. Illustration of the pyramid presented on the computer screen during the experimental task in all experiments. 
Pressing the blue or yellow keys moved the cursor according to three types of schedules: VI, FT, and FR. For all schedules, pressing either key was counted as a valid response. Each type of schedule comprised two values (cf. LeFrancois et al., 1988), 5 and 15, and was correlated with a specific cursor color: purple for the VI, blue for the FT, and green for the FR. During the VI schedule, the first press on any key (blue or yellow) after an average interval of $5 \mathrm{~s}$ (or $15 \mathrm{~s}$ ) moved the cursor. During the FT schedule, the cursor moved after $5 \mathrm{~s}$ (or $15 \mathrm{~s}$ ) regardless of presses on either key and according to sequences of eight movements determined by the computer. During the FR schedule, only the 5th (or 15th) press moved the cursor. The last key press determined whether the movement of the cursor would be to the left or to the right. In all schedules, one point was earned when the cursor reached the bottom of the pyramid. When a point was earned, a beep sounded and the message "Press the space bar" was shown below the pyramid. After the participant pressed the space bar, the point was registered on the counter located at the upper right corner of the screen, and the cursor was again presented at the top of the pyramid.

Each schedule value was presented for three consecutive 3-min cycles, such that each training session comprised 18 cycles. The order of schedule presentation was counterbalanced across participants. For example, participant VSR1 was exposed to the following sequence of schedules within the training session: FT 5-FT 5-FT 5-VI 15-VI 15-VI 15-FR 5-FR 5-FR 5-FT 15-FT 15-FT 15-FR 15-FR 15-FR 15-VI 5-VI 5-VI 5. There was an intercycle interval (ICI) during which rules were collected or presented to the groups (self-rule and rule groups, respectively) or no rules were collected or presented (control groups).

For participants in the varied self-rule (VSR) group, the following information was added to the initial instruction between paragraphs 2 and 3:

At certain points of the session, you will be asked to point out the best way to move the colored square. You may choose one alternative from those shown on the screen. To do so, click with the mouse on the chosen alternative. You may change your choice by clicking on another alternative. To confirm your choice, click on the word CONFIRM.

During the ICIs, each participant was asked to indicate the best way to move the cursor by choosing one of the four alternatives presented on the screen:

The best way to move the colored square through the pyramid is by

(a) pressing the keys after a variable time

(b) pressing the keys a fixed number of times

(c) pressing the keys alternately

(d) moving the colored square does not depend on pressing keys

To choose one alternative, the participant had to click on it with the mouse. Changing choices was possible within a period of $3 \mathrm{~s}$. After that period, the word "Confirm" appeared at the bottom of the screen, and the participant 
was required to click on it to register the last choice made and start another cycle (or end the session).

There was one training session per day. If the participant did not present accurate self-rules in the last two cycles of each of the last three types of schedules by the fourth training session, his or her participation in the study was ended.

For participants in the varied rule (VR) group, the following information was included between paragraphs 2 and 3 of the initial instruction: "At certain points of the session, you will receive instructions about the best way to move the colored square." Each participant in this group was yoked, during the training phase, to a participant of the VSR group in terms of the order of schedule presentation, number of training sessions, duration of the ICIs, and rules. For example, participant VR1 was yoked to participant VSR1, participant VR2 was yoked to participant VSR2, and so on. The yoking of the rules was done by displaying on the screen, during the ICI, the alternative chosen by a matched participant of the VSR group for that specific ICI, despite the accuracy of the alternative.

Participants in the varied control (VC) group received only the initial instructions and were yoked to participants of the VSR group with respect to order of schedule presentation, number of sessions, and duration of ICIs (e.g., participant VC1 was yoked to participant VSR1, participant VC2 was yoked to participant VSR2, and so on). These participants neither generated nor received rules in the ICIs, during which the screen was gray and blank.

When a participant in the VSR group met the training criterion, the next session for him or her (and for yoked participants) consisted of a brief exposure to the training phase followed immediately by the testing phase. This brief training was similar to the previous training sessions except for the number of cycles of each type of schedule: a cycle with one of the VI (or FT) values, another cycle with one of the FT (or VI) values, and a last cycle with the FR 15 schedule (total number of three cycles). The values of the VI and FT schedules, as well as the order of presentation of those schedules, were varied across participants. At the end of each schedule, participants in the VSR group were required to select a rule. If accurate self-rules for each schedule were selected, the testing phase was initiated. Otherwise, the participant (and the yoked ones in the other two groups) was dismissed.

Specific groups. The participants in these groups were exposed only to the FR schedule. During the training phase, each schedule value (FR 5 and FR 15) was in effect for three successive 3-min cycles. Training sessions comprised 18 cycles, 9 cycles per schedule value. The order of presentation of those schedule values was counterbalanced across participants.

For participants in the specific self-rule (SSR) group, instructions were the same as for participants in the VSR group except for the message given during the ICIs:

The best way to move the colored square through the pyramid is by

(a) pressing the keys a fixed number of times

(b) pressing the keys alternately

If accurate self-rules were not provided by the fourth session, the participant was dismissed. 
An initial instruction identical to that presented to the VR group was given to participants in the specific rule (SR) group. Each participant was yoked to one participant in the SSR group in terms of the order of schedule presentation, number of training sessions, duration of the ICIs, and rules. These participants were given the rules chosen by the participants of the SSR group in a manner similar to that employed with the VR group.

Each participant in the specific control (SC) group received only the initial instruction and was yoked to one participant in the SSR group with respect to the order of schedule presentation, number of training sessions, and duration of ICIs. As for the VC group, these participants did not generate and did not receive rules during the ICIs.

After the training criterion was met by a participant in the SSR group, he or she (and yoked participants) was exposed to a brief training session followed by the testing phase. During this brief training, which contained a total of three cycles, participants in the specific groups were exposed to both FR values, such that this session always ended after the FR 15 schedule. If accurate self-rules were not obtained after each cycle, self-rule participants, and the yoked ones, were dismissed.

\section{Testing Phase}

This phase was identical for all participants in the varied and specific groups. During this phase, blue and yellow key presses moved the cursor according to an FI 15-s schedule, which was correlated with an orange color. As in the training phase, points were earned when the cursor reached the bottom row of the pyramid. At the beginning of this phase, the participants received the following message: "You have to discover the best way to move the square." Participants were neither required to provide nor received rules. This session lasted for $30 \mathrm{~min}$.

\section{Results and Discussion}

\section{Training}

Three participants of the VSR group did not show accurate self-rules by the fourth session of the training phase and thus were dismissed from the experiment. All participants in the SSR group provided accurate self-rules (data not shown).

Table 2 shows response rates during the brief exposure to the training phase for each participant in the varied and specific groups. For all participants in the varied groups, FR rates were higher than VI and FT rates (except for participant VC4), and VI rates tended to be either similar to or higher than FT rates (again, except for participant VC4). All participants in the specific groups showed stable FR response rates across all cycles, comparable to those observed for participants in the varied groups. These results were observed despite the presence or absence of rules (and selfrules). These findings are consistent with those obtained by Rosenfarb et al. (1992) and indicate that verbal descriptions of the schedules (i.e., self-rules and rules) are not necessary for the development of differentiated response rates. 
Table 2

Response Rates (Responses per Second) for Each Participant of the Varied and Specific Groups in the Brief Exposure to the Training Phase of Experiment 1

\begin{tabular}{|c|c|c|c|c|c|c|}
\hline Schedule & Participant & $R / s$ & Participant & $R / s$ & Participant & $\mathrm{R} / \mathrm{s}$ \\
\hline & \multicolumn{6}{|c|}{ Varied } \\
\hline & \multicolumn{2}{|c|}{ Self-rule } & \multicolumn{2}{|c|}{ Rule } & \multicolumn{2}{|c|}{ Control } \\
\hline VI 5 & VSR1 & 0.2 & VR1 & 0.2 & $\mathrm{VCl}$ & 2.8 \\
\hline FT 15 & & 0.1 & & 0.0 & & 1.3 \\
\hline FR 15 & & 1.9 & & 4.3 & & 3.9 \\
\hline FT 15 & VSR2 & 0.1 & VR2 & 0.0 & VC2 & 0.0 \\
\hline VI 5 & & 0.1 & & 0.2 & & 0.1 \\
\hline FR 15 & & 4.5 & & 5.0 & & 4.6 \\
\hline FT 15 & VSR3 & 0.4 & VR3 & 0.9 & VC3 & 0.9 \\
\hline VI 5 & & 1.7 & & 0.4 & & 0.2 \\
\hline FR 15 & & 5.7 & & 4.6 & & 3.9 \\
\hline VI 15 & VSR4 & 0.4 & VR4 & 2.6 & VC4 & 3.5 \\
\hline FT 5 & & 0.1 & & 0.6 & & 5.2 \\
\hline \multirow[t]{3}{*}{ FR 15} & & 2.9 & & 2.9 & & 4.5 \\
\hline & \multicolumn{6}{|c|}{ Specific } \\
\hline & \multicolumn{2}{|c|}{ Self-rule } & \multicolumn{2}{|c|}{ Rule } & \multicolumn{2}{|c|}{ Control } \\
\hline FR 15 & SSR5 & 5.6 & SR5 & 5.8 & SC5 & 5.6 \\
\hline FR 15 & & 5.3 & & 6.1 & & 5.8 \\
\hline FR 15 & & 5.3 & & 6.1 & & 6.0 \\
\hline FR 5 & SSR6 & 5.9 & SR6 & 6.8 & SC6 & 3.8 \\
\hline FR 15 & & 5.3 & & 6.2 & & 4.2 \\
\hline FR 15 & & 5.1 & & 5.2 & & 3.8 \\
\hline FR 5 & SSR7 & 4.8 & SR7 & 4.6 & SC7 & 4.0 \\
\hline FR 15 & & 5.2 & & 4.1 & & 4.3 \\
\hline FR 15 & & 4.6 & & 3.8 & & 4.3 \\
\hline FR 15 & SSR8 & 4.6 & SR8 & 3.4 & SC8 & 6.0 \\
\hline FR 15 & & 4.2 & & 3.6 & & 6.0 \\
\hline FR 15 & & 4.6 & & 3.8 & & 6.0 \\
\hline
\end{tabular}

\section{Testing}

Sensitivity to the FI schedule was evaluated with a resistance-to-change measure. Resistance to change is defined as the extent to which response rate changes after some environmental condition is changed (Grace, Schwendiman, \& Nevin, 1998). To allow comparison between FI and FR response rates (the FR was the last training schedule presented before the FI schedule), the testing session was also divided into 3-min cycles. Resistance was calculated by 
dividing FI response rate in each cycle by the mean FR response rate from all FR cycles during the brief exposure to the training phase. Resistance values close to 1.0 indicate no change in response rates despite the change from the FR to the FI schedule (insensitivity); values below 1.0 indicate decreases in

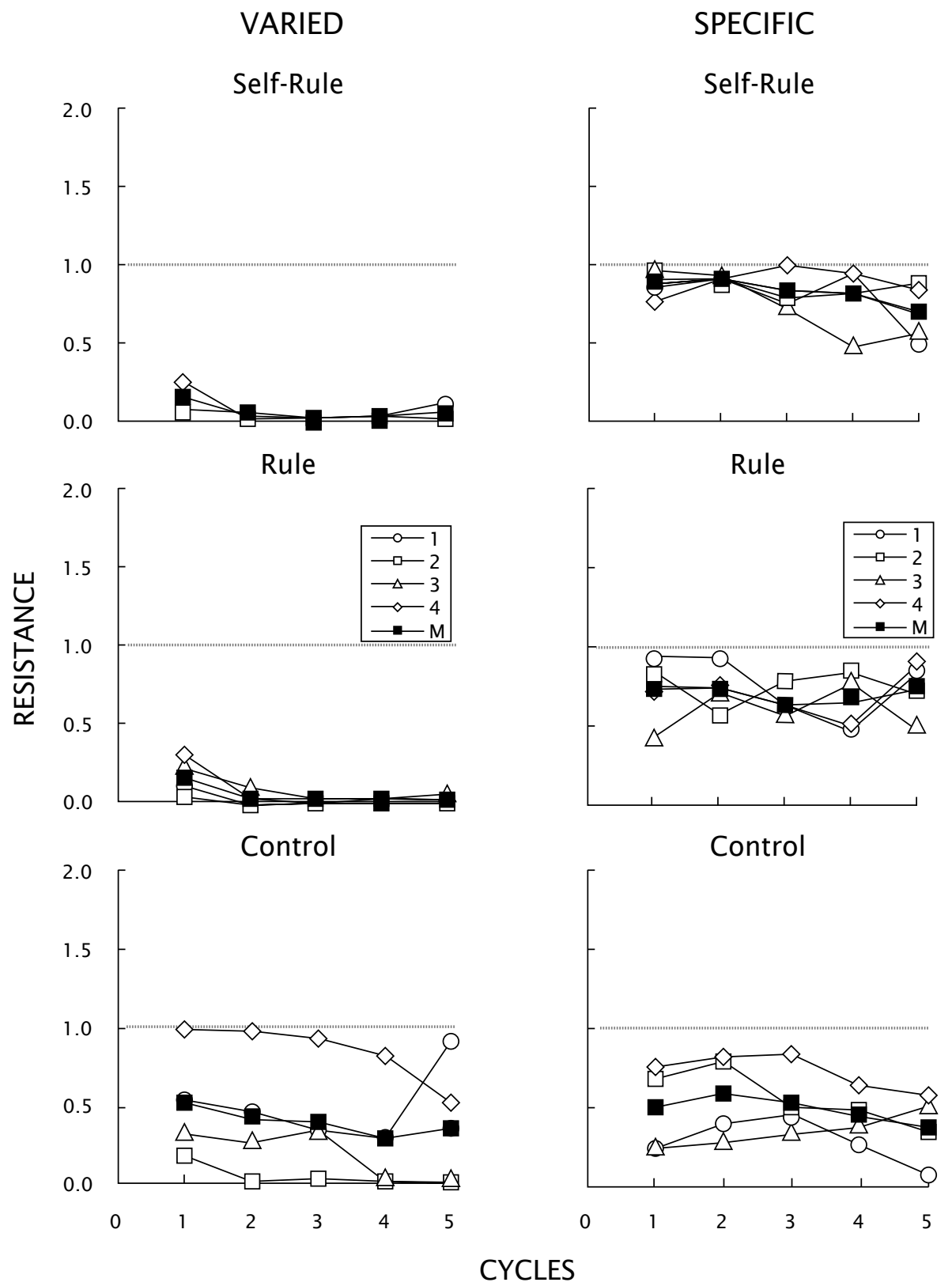

Figure 2. Resistance to schedule change, from $\mathrm{FR}$ to $\mathrm{Fl}$, for each participant in the varied and specific groups in Experiment 1. Mean values are indicated by the filled squares. 
response rates, while values above 1.0 indicate increases in response rates relative to the FR-obtained rates (sensitivity). Although decreases or increases in response rates due to the schedule change indicate sensitivity (Madden et al., 1998), only response rate decreases may be considered an efficient change after the implementation of the FI schedule.

Figure 2 shows the resistance measure for the response rates (hereafter called response-rate resistance) obtained in the first five cycles of the testing phase. Response-rate resistance is presented for each participant (open symbols) in the varied (left panels) and specific (right panels) groups. The mean values for each group are also shown (filled squares). With the introduction of the FI schedule, response rates were reduced for all participants in the VSR and VR groups. Smaller response rate reductions or no reductions in response rates, however, were observed for almost all participants in the remaining groups, especially for those in the SSR and SR groups.

In summary, in the absence of self-rules or rules, a history with varied schedules or a specific schedule produced comparable levels of sensitivity to the FI schedule (VC and SC groups). However, greater levels of sensitivity were observed with varied self-rules (and rules) than with a specific self-rule (and rule), a result that replicates those reported by LeFrancois et al. (1988). Moreover, as in the study of Rosenfarb et al. (1992), there was no difference between self-rules and rules groups.

Several concerns, however, can be raised regarding the results obtained in Experiment 1. First, it may be argued that the results of both the self-rules and rules groups do not truly reflect functional similarities. In fact, those similarities may be an artifact of the procedure used to collect self-rules. Specifically, it can be argued that with multiple-choice questions, the alternatives may function as rules, and as a consequence, the participants may be compelled to behave accordingly. Second, the varied training employed in the present experiment was designated to separate the effects of varied schedules and varied rules by adding a control group that was not evaluated in the LeFrancois et al. (1988) study. The results suggested that the effects of the varied training were greater when rules and self-rules were present than in their absence. Nevertheless, the training comprised schedules that produced response differentiation, and it seems possible that response-rate differentiation may have contributed to the greater behavioral sensitivity displayed by the VSR and VR participants. Third, the differential resistance to change (or sensitivity) observed for the varied and specific groups may be attributed to the differential number of reinforcers received under each reinforcement schedule. A number of studies have shown that resistance to change is directly related to the number of reinforcers obtained in one context (e.g., Grace, McLean, \& Nevin, 2003). Because the specific groups had a larger exposure to the FR schedule than the varied groups (18 cycles versus 6 cycles, respectively) and therefore had three times more opportunities to earn FR reinforcers, this variable, instead of the limited behavioral repertoire, may have promoted the higher resistance observed for those groups. Each of those concerns was addressed in the next three experiments.

\section{EXPERIMENT 2}

In Experiment 1, self-rule participants had to choose among four alternatives in describing the schedule in effect. The alternatives were provided to narrow the range of rules by each participant and, hence, to 
increase the chance of obtaining accurate descriptions in a reasonable period of time. Because the alternatives may have functioned as rules, Experiment 2 replaced the multiple-choice question with an open-ended question.

\section{Method}

\section{Participants}

Sixteen students from the Universidade de Brasília (10 women and 6 men) participated in this experiment. They ranged in age from 18 to 50 years, and none had experience with operant conditioning experiments. At the beginning of the experiment, participants were asked to read and sign an informed consent. Reinforcers (extra credit in psychology courses and the cash prize) were programmed as in Experiment 1.

\section{Setting and Apparatus}

The setting and apparatus were identical to those in Experiment 1.

\section{Procedure}

All participants were exposed to two experimental phases: training and testing. During the training phase, participants were divided into four groups: VSR, VR, SSR, and SR (see Table 1).

\section{Training Phase}

This phase was similar to that of Experiment 1 except for the procedures employed to generate self-rules and to provide rules. Instead of choosing among alternatives displayed on the computer screen, participants in the VSR and SSR groups in the present experiment had to write on a card the best way to move the cursor. Similarly, for participants in the VR and SR groups, yoked rules were given on a card and not on the computer screen, as occurred in Experiment 1.

At the beginning of the session, participants in the VSR and SSR groups were given the same initial instruction provided to participants in the varied groups of Experiment 1, with the following information added between paragraphs 2 and 3:

At certain points of the session, the screen will be gray. Whenever this happens, ring the bell located at the right side of the computer. The experimenter will then pass you a card beneath the door. On this card, you must describe the best way to move the colored square through the pyramid. You will have 1 minute to write down your description. After that period, please pass the card back to the experimenter.

After each 3-min cycle of schedule exposure, there was an interval during which the participant was required to describe the best way to move the cursor. A blank gray screen signaled the ICI. At this point, the participant rang a bell, and the experimenter slid a card beneath the door. The participant then had approximately $1 \mathrm{~min}$ to write the rule on the card and give it back to the experimenter. 
Participants in these two groups were moved to the brief training session when the following criterion was met, regardless of self-rule accuracy: the VI, FT, and FR schedules produced differentiated response rates (for the VSR group), or the FR response rates were comparable to those obtained with the FR schedule of the VSR group (for the SSR group). If this criterion was not reached in four sessions, the participant was dismissed from the experiment.

For participants in the VR and SR groups, the following information was added between paragraphs 2 and 3 of the initial instruction described for participants in the varied groups of Experiment 1:

At certain points of the session, the screen will be gray. Whenever this happens, ring the bell located at the right side of the computer. The experimenter will then pass you a card beneath the door. This card will contain instructions regarding the best way to move the colored square through the pyramid. You will have 1 minute to read the instructions. After that period, please pass the card back to the experimenter.

The self-rules provided by each participant of the VSR and SSR groups were typed on a card and given to the yoked participant of the VR or SR groups, respectively, regardless of their accuracy. During the ICI, after the participant rang the bell, the experimenter slid the card with the written rule beneath the door. The participant had $1 \mathrm{~min}$ to read the card and give it back to the experimenter.

After the training criterion was met by a participant in the self-rule groups, the next session comprised a brief training, followed by the testing phase, as in Experiment 1. During this brief training, all participants were exposed to only three 3-min cycles. As in Experiment 1, participants were required to generate (or received) rules, but unlike Experiment 1, rule accuracy was not required to move to the next phase. Participants in the varied groups were exposed to one of the two values of the VI and FT schedules and then to the FR 15 schedule. Participants in the specific groups were exposed to the two values of the FR schedule, but the last one was always the FR 15 schedule.

\section{Testing Phase}

During the testing phase, an FI 15-s schedule was in effect as in Experiment 1, but due to a programming error, session duration was $21 \mathrm{~min}$ (instead of $30 \mathrm{~min}$ as in Experiment 1) for all groups.

\section{Results and Discussion}

\section{Training}

Table 3 shows the self-rules provided by each participant in the VSR and SSR groups during the brief training session. Most participants in the VSR group presented accurate (e.g., "Just waiting" for the FT 5 s), or at least close to accurate (e.g., "Waiting 8 seconds"), self-rules. Only three self-rules indicated no schedule discrimination: two for the VI 5 s ("I observed nothing" and "Pressing 'F' or 'J' until the square goes down") and one for the FR 15 ("Pressing ' $F$ ' or ' $J$ '”). All participants of the SSR group accurately described the FR schedule. 
Table 3

Self-Rules Presented by Each Participant of the Varied Self-Rule and Specific Self-Rule Groups in the Brief Exposure to the Training Phase of Experiment 2

\begin{tabular}{|c|c|c|}
\hline Participants & Schedule & Self-rule \\
\hline \multicolumn{3}{|r|}{ Varied self-rule group } \\
\hline \multirow[t]{3}{*}{ VSR5 } & VI 5 & "I observed nothing" \\
\hline & FT 15 & $\begin{array}{l}\text { "The blue square moved in a random manner, } \\
\text { without pressing the buttons, most of the time } \\
\text { in intervals of } 18 \text { seconds, more or less" }\end{array}$ \\
\hline & FR 15 & $\begin{array}{l}\text { "The square moved after } 15 \text { presses } \\
\text { on the yellow button" }\end{array}$ \\
\hline \multirow[t]{3}{*}{ VSR6 } & FT 5 & $\begin{array}{l}\text { "Staying quiet, and waiting for the square to } \\
\text { move down" }\end{array}$ \\
\hline & VI 15 & "Waiting 20 seconds and then pressing any button" \\
\hline & FR 15 & "Pressing many times any button" \\
\hline \multirow[t]{3}{*}{ VSR7 } & FT 5 & "Waiting 8 seconds" \\
\hline & VI 15 & $\begin{array}{l}\text { "Pressing one button, waiting some seconds, } \\
\text { and then pressing another button" }\end{array}$ \\
\hline & FR 15 & "Pressing 15 times each button" \\
\hline \multirow[t]{3}{*}{ VSR8 } & VI 5 & "Pressing ' $\mathrm{F}$ ' or 'J' until the square goes down" \\
\hline & FT 15 & "Just waiting" \\
\hline & FR 15 & "Pressing 'F' or 'J'” \\
\hline
\end{tabular}

Specific self-rule group

\begin{tabular}{|c|c|c|}
\hline \multirow[t]{3}{*}{ SSR5 } & FR 5 & $\begin{array}{l}\text { "By pressing the buttons } 5 \text { times, the square goes } \\
\text { down one time" }\end{array}$ \\
\hline & FR 15 & $\begin{array}{l}\text { "By pressing the buttons } 15 \text { times, } \\
\text { the square goes down one time" }\end{array}$ \\
\hline & FR 15 & $\begin{array}{l}\text { "By pressing the buttons } 15 \text { times, } \\
\text { the square goes down one time" }\end{array}$ \\
\hline \multirow[t]{3}{*}{ SSR6 } & FR 5 & "Pressing the blue or yellow buttons 40 times" \\
\hline & FR 15 & $\begin{array}{l}\text { "Pressing the blue or yellow buttons } 120 \text { times } \\
\text { and the white button (to get the points)" }\end{array}$ \\
\hline & FR 15 & $\begin{array}{l}\text { "Pressing the blue or yellow buttons } 120 \text { times } \\
\text { and the white button at the end" }\end{array}$ \\
\hline \multirow[t]{3}{*}{ SSR7 } & FR 5 & “5 times 'F' or 5 times 'J' / 8 times" \\
\hline & FR 5 & "5 times 'F' or 5 times 'J' / 8 times" \\
\hline & FR 15 & "15 times 'F' or 5 times 'J' / 8 times" \\
\hline \multirow[t]{3}{*}{ SSR8 } & FR 5 & $\begin{array}{l}\text { "Pressing the buttons } 40 \text { times (in a random } \\
\text { manner, without interruptions)" }\end{array}$ \\
\hline & FR 5 & $\begin{array}{l}\text { "Pressing each step } 5 \text { times or } 40 \text { from the top } \\
\text { to the base" }\end{array}$ \\
\hline & FR 15 & $\begin{array}{l}\text { "The best way is by pressing } 40 \text { times, } \\
\text { although I had to press } 120 \text { times now" }\end{array}$ \\
\hline
\end{tabular}


Response rates for each participant of the varied and specific groups during the brief exposure to the training conditions are shown in Table 4. For all participants in the VSR and VR groups, the highest rates were obtained with the FR schedule; VI rates, on the other hand, tended to be similar to the FT rates, with the exception of participants VSR12 and VR9. For participants in the SSR and SR groups, the FR schedules yielded response rates comparable to those observed for the varied groups when exposed to the same schedule.

Table 4

Response Rates (Responses per Second) for Each Participant of the Varied and Specific Groups in the Brief Exposure to the Training Phase of Experiment 2

\begin{tabular}{ccccc}
\hline Schedule & Participant & R/s & Participant & R/s \\
\cline { 2 - 5 } & \multicolumn{3}{c}{ Varied } \\
nyyyy VI 5 & Self-rule & \multicolumn{3}{c}{ Rule } \\
\cline { 2 - 5 } FT 15 & VSR9 & 0.4 & VR9 & 3.5 \\
FR 15 & & 0.2 & & 1.5 \\
FT 5 & VSR10 & 1.2 & & 4.1 \\
VI 15 & & 0.0 & VR10 & 0.1 \\
FR 15 & & 0.2 & & 0.6 \\
FT 5 & VSR11 & 2.4 & & 4.6 \\
VI 15 & & 0.4 & VR11 & 0.0 \\
FR 15 & & 0.5 & & 0.1 \\
VI 5 & VSR12 & 5.0 & & 5.4 \\
FT 15 & & 5.2 & VR12 & 0.2 \\
FR 15 & & 1.0 & & 0.5 \\
& & 5.5 & & 4.4
\end{tabular}

Specific

FR 5

FR 15

FR 15

FR 5

FR 15

FR 15

FR 5

FR 5

FR 15

FR 5

FR 5

FR 15

\begin{tabular}{cccc}
\hline \multicolumn{3}{c}{ Self-rule } & \multicolumn{2}{c}{ Rule } \\
\hline SSR13 & 4.0 & SR13 & 6.3 \\
& 3.7 & & 6.0 \\
\multirow{3}{*}{ SSR14 } & 4.5 & & 5.9 \\
& 4.9 & SR16 & 5.9 \\
& 4.9 & & 5.6 \\
SSR15 & 5.0 & & 5.3 \\
& 5.2 & SR15 & 6.0 \\
& 4.7 & & 6.0 \\
SSR16 & 5.0 & & 5.9 \\
& 4.9 & SR16 & 5.2 \\
& 4.6 & & 6.3 \\
& 4.4 & & 5.9 \\
\hline
\end{tabular}




\section{Testing}

Figure 3 presents response-rate resistance obtained in the first five cycles of the testing phase for each participant in the varied (left panels) and specific (right panels) groups. Mean values are represented by the filled squares. The schedule change from FR to FI reduced response rates for all participants in both VSR and VR groups. For all participants in the specific groups, the implementation of the FI schedule also decreased response rates, but this effect was weaker (SSR group) or transitory (SR group) when compared to the effect obtained with participants in the varied groups.
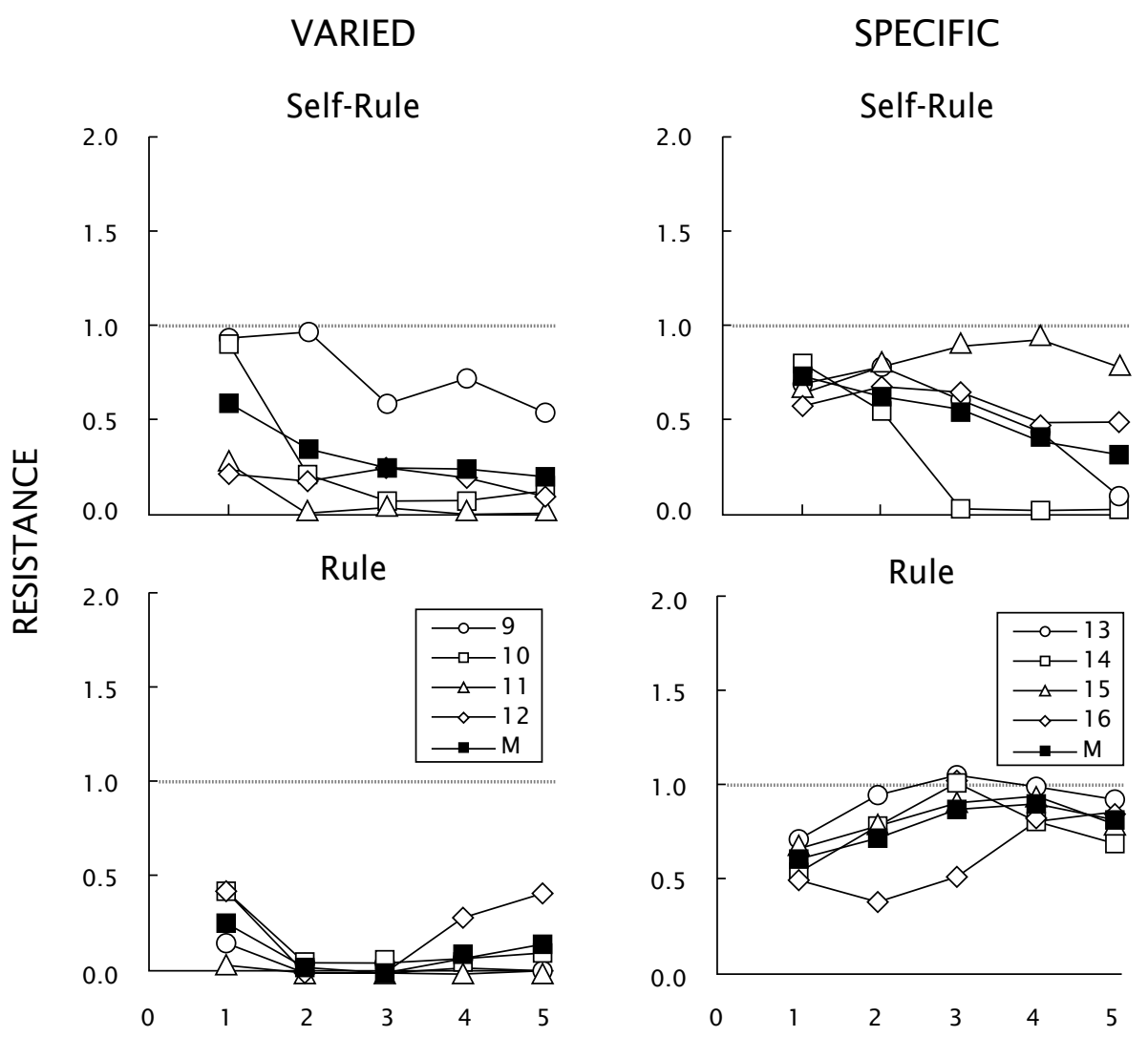

\section{CYCLES}

Figure 3. Resistance to schedule change, from FR to FI, for each participant in the varied and specific groups in Experiment 2. Mean values are indicated by the filled squares.

As was observed in Experiment 1, Figure 3 indicates that self-rules and rules generated performances that were similarly sensitive to schedule changes, and that previous experience with varied contingencies (several schedules and rules) yielded greater sensitivity to the programmed changes than a reinforcement history restricted to only one contingency (one schedule and one rule). The difference between FI response rates shown by participants in the varied and specific groups was comparable to that of 
Experiment 1, suggesting that the way self-rules are established may not be a critical variable for behavioral sensitivity. This result should be expected if self-rules and rules were functionally similar. If the response alternatives in a multiple-choice question may function as instructional stimuli, and hence may constrain the content of self-rules, and if rules and self-rules affect sensitivity in a similar manner, then "constrained" and "unconstrained" self-rules should be part of the same functional class and have comparable effects upon sensitivity.

\section{EXPERIMENT 3}

In Experiment 1, participants in the varied groups were exposed to three different schedules (VI, FT, and FR) and to accurate (or close to accurate) rules (generated by the participant or given by the experimenter). These schedules and rules were accompanied by differentiated response rates (high, intermediate, or low). By visually comparing the results of the VSR and VR groups with those of the VC group, it can be seen that sensitivity was greater (or resistance to change was lower) for the first two groups than for the latter one. Moreover, there were no differences in sensitivity between the VC and the SC groups. Taken together, these results suggested that a history with varied schedules promoted sensitivity as long as self-rules and rules were present. However, because the effects of differentiated response rates were not disentangled from those of the schedules and/or rules in Experiments 1 and 2 , the contribution of response-rate differentiation to sensitivity remains to be determined.

Experiment 3 aimed, therefore, to evaluate the extent to which sensitivity to the FI schedule was influenced by previous exposure to varied contingencies and/or to differentiation in response rates. In this experiment, participants were exposed to three types of schedules that produced similar response rates: random ratio (RR), VR, and FR. If we consider the high rate of responding shown by participants in the specific groups, who were exposed to only one schedule (FR) in Experiments 1 and 2, two predictions are possible for Experiment 3. If the critical variable in the previous experiments was exposure to several self-rules and rules, then behavioral sensitivity for the present groups should be similar to that of the varied groups in Experiments 1 and 2, and greater than that of the specific groups in those experiments. However, if response-rate differentiation is an important variable, behavioral sensitivity for the present groups should be comparable to that shown by the specific groups in Experiment 1 and 2.

\section{Method}

\section{Participants}

Twelve students from the Universidade de Brasília (7 women, 5 men) participated in this experiment to earn extra credit in introductory psychology classes. They ranged in age from 17 to 31 years old and had no previous experience with operant research experiments. At the beginning of the experiment, participants were asked to read and sign an informed consent. A cash prize was in effect as in the previous experiments. 


\section{Setting and Apparatus}

The setting and apparatus were identical to those in Experiment 1.

\section{Procedure}

This experiment comprised two phases, training and testing, and three groups, VSR, VR, and VC (see Table 1). The procedure differed from that used with the varied groups in Experiment 1 with respect to the schedules, the alternatives available for the self-rules, the strategy to present rules, and the criteria to end the training phase.

\section{Training Phase}

All participants were exposed to three types of schedules, each of them with two values: RR 5, RR 15, VR 5, VR 15, FR 5, and FR 15. Each schedule was signaled by a specific color: gray for RR, red for VR, and green for FR. During the RR schedule, presses on either the blue or yellow key moved the cursor with a probability equal to 0.2 (RR 5) or 0.067 (RR 15). During the VR schedule, the first press on any key after an average number of presses (5 or 15) moved the cursor. The FR schedules were identical to those in Experiment 1. Each schedule was presented for three consecutive 3-min cycles, and the session comprised 18 cycles. As in Experiment 1, points were earned when the cursor reached the bottom of the pyramid.

When asked to describe the schedule, participants of the VSR group had to choose one of the following alternatives:

The best way to move the colored square through the pyramid is by

(a) pressing the keys a variable number of times

(b) pressing the keys a fixed number of times

(c) pressing the keys alternately

(d) pressing the keys a random number of times

In Experiment 1, each participant in the VR group was given the self-rules presented by a yoked participant in the VSR group. This procedure was not used in the present experiment. In a pilot study, participants in the VSR group showed high and undifferentiated response rates and usually described all schedules similarly. It could be argued, therefore, that the effects of response differentiation and varied rules could not be disentangled with this design. To avoid this confounding effect, participants of the VR group were not yoked to participants of the VSR group regarding the rules. That is, participants of the VR group received from the experimenter accurate rules for each schedule throughout the training sessions. By providing accurate rules for this group, the effects of accurate varied rules in the absence of response differentiation could be evaluated when the testing phase was in effect. The provided rules were identical to the alternatives ( $a, b$, or d) presented to the VSR group.

The criterion to move to the brief training session was that high response rates (at least four responses per second) had to be obtained in the last two cycles of each of the last three types of schedules in no longer than four sessions. The brief training occurred the next day and comprised three 
3-min cycles with one of the values of the RR, VR, and FR schedules. Unlike the previous experiments, the last schedule for all participants was the VR, and not the FR, due to a programming error. The remaining aspects of the procedure matched those in Experiment 1.

\section{Testing Phase}

The testing phase was identical to the one described in Experiment 1.

\section{Results and Discussion}

\section{Training}

During the brief training session, participant VSR19 provided accurate self-rules for the FR and VR schedules, while the remaining participants of the VSR group did the same only for the FR schedule (data not shown). Table 5 presents response rates during the brief exposure to the training phase for each participant of the varied groups. Similar response rates were obtained for all participants under the FR, VR, and RR schedules. Moreover, response rates were comparable to those obtained with the FR schedules in the previous experiments. These results showed that the training conditions with three different schedules of reinforcement engendered undifferentiated response rates, regardless of the presence or absence of explicit verbal stimuli (self-rules and rules) and the accuracy of those verbal stimuli.

Table 5

Response Rates (Responses per Second) for Each Participant of the Varied Groups in the Brief Exposure to the Training Phase of Experiment 3

\begin{tabular}{ccccccc}
\hline Schedule & Participant & R/s & Participant & R/s & Participant & R/s \\
\hline & \multicolumn{5}{c}{ Varied } \\
nyyyyyy FR 5 & VSR17 & 6.4 & VR17 & 4.4 & VC17 & 5.2 \\
nR 15 & & 4.8 & & 4.3 & & 5.3 \\
VR 5 & & 6.5 & & 4.1 & & 5.3 \\
FR 5 & VSR18 & 5.9 & VR18 & 4.8 & VC18 & 5.3 \\
RR 15 & & 5.7 & & 4.7 & & 4.4 \\
VR 15 & & 5.0 & & 4.4 & & 2.9 \\
RR 5 & VSR19 & 2.9 & VR19 & 3.6 & VC19 & 6.0 \\
FR 15 & & 3.7 & & 2.8 & & 5.2 \\
VR 15 & & 3.7 & & 3.2 & & 5.7 \\
FR 5 & VSR20 & 5.3 & VR20 & 5.5 & VC20 & 5.7 \\
RR 15 & & 6.4 & & 4.4 & & 5.5 \\
VR 15 & & 3.9 & & 5.1 & & 5.2 \\
\hline
\end{tabular}




\section{Testing}

Figure 4 shows response-rate resistance obtained in the first five cycles of the testing phase for each participant of the varied groups. Filled squares correspond to the mean values. Response rates were reduced for most participants in all groups after the introduction of the FI schedule, except for participants VC18 and VC20. However, this reduction was not as great as that observed for the participants of the varied groups in Experiments 1 and 2. As was observed for the participants of the specific groups in the previous experiments, most participants showed substantial responding throughout the FI cycles (except for participants VSR20 and VC19).

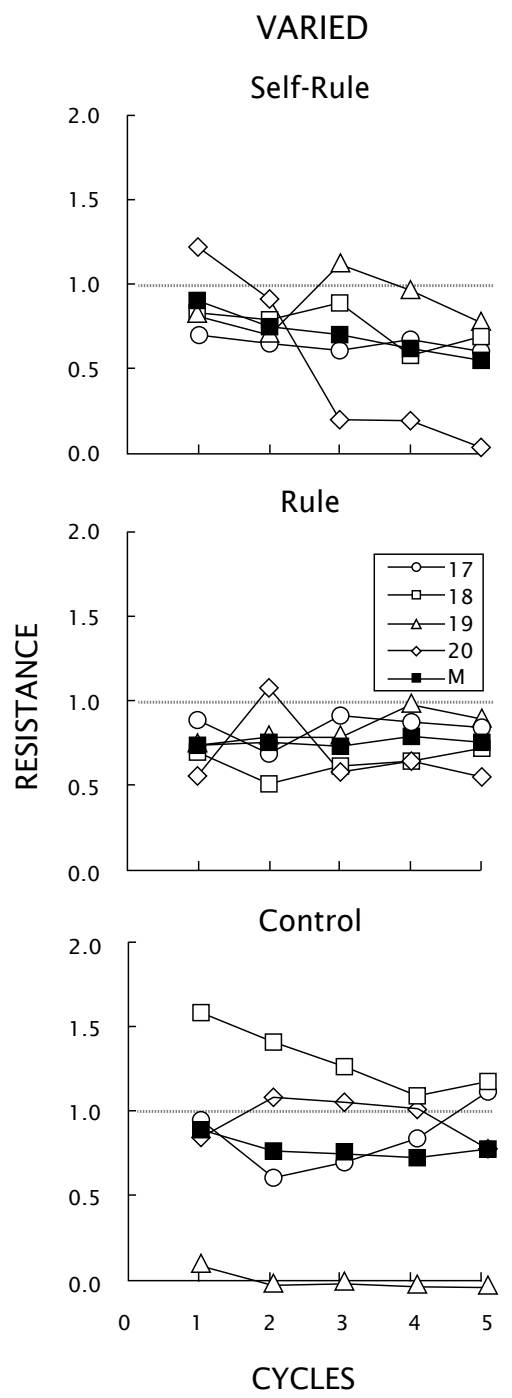

Figure 4. Resistance to schedule change, from FR to FI, for each participant in the varied groups in Experiment 3. Mean values are indicated by the filled squares. 
All varied groups in Experiments 1, 2, and 3 were exposed to three different types of schedules in the training phase. In Experiments 1 and 2, training conditions generated high, intermediate, and low response rates across schedules for participants of the varied groups, and sensitivity to change was observed. In Experiment 3, on the other hand, undifferentiated response rates were obtained for the participants of the varied groups, and insensitivity followed the schedule change. Those results suggest that response-rate differentiation was a critical variable to sensitivity under the contingencies arranged throughout this study.

\section{EXPERIMENT 4}

Several studies have demonstrated that resistance to change is a direct function of the number of reinforcers received during previous experimental conditions (e.g., Nevin, 1974, 2002). Accordingly, in Experiments 1 and 2, the numbers of reinforcers may have been a confounding variable affecting behavioral sensitivity. That is, the higher resistance to change (lower sensitivity) shown by the participants in the specific groups, as compared to the participants in the varied ones, could be attributed to the larger number of FR reinforcers obtained by the former participants. To evaluate the role of number of reinforcers upon sensitivity of behavior under the control of rules and self-rules, the number of FR cycles for the specific groups were equated to the number of FR cycles for the varied groups in the previous experiments. With this manipulation, the number of reinforcers tended to be similar across those groups.

\section{Method}

\section{Participants}

Twelve students from the Universidade de Brasília (10 women and 2 men) participated in this experiment. They ranged in age from 18 to 25 years old. At the beginning of the experiment, participants were asked to read and sign an informed consent. Reinforcers (extra credit in psychology courses and the cash prize) were programmed as in Experiment 1.

\section{Setting and Apparatus}

The setting and apparatus were identical to those in Experiment 1.

\section{Procedure}

All participants were exposed to two experimental phases: training and testing. During the training phase, participants were divided into three groups: SSR, SR, and SC (see Table 1).

\section{Training Phase}

The training phase was similar to that of the specific groups in Experiment 1 except for the number of cycles and the strategy to provide rules. In Experiment 1, participants in the specific groups were exposed to 18 cycles, whereas participants in the varied groups were exposed to only 6 
cycles of the FR schedule. To rule out this extraneous variable, in the present experiment participants of the specific groups were exposed only to 6 cycles of the FR schedule.

Participants were exposed to three cycles of the FR 5 schedule and three cycles of the FR 15 schedule before moving to the brief training session. The order of presentation of the FR values was counterbalanced across participants. When the above criterion was reached, participants were exposed to only one cycle of the FR schedule (similar to the brief training session of Experiments 1, 2, and 3), followed by the testing phase.

Participants in the SR group were not yoked to participants in the SSR group due to a computer malfunction that resulted in the loss of the SSR group's verbal description data. Instead, participants in the SR group were provided accurate descriptions of the prevailing schedules. All of the remaining procedural details matched those in Experiment 1.

\section{Testing Phase}

As in Experiment 1, participants were exposed to a FI 15-s schedule.

\section{Results and Discussion}

\section{Training}

All participants in the SSR group presented accurate self-rules (data not shown). Table 6 shows response rates during the brief exposure to the training phase for each participant in the specific groups. Response rate values were similar across all three groups and were not distinguishable from those obtained with the FR schedules in Experiments 1, 2, and 3. Also, the number of FR reinforcers for all participants was similar to that of participants in the varied groups in the previous experiments (data not shown).

Table 6

Response Rates (Responses per Second) for Each Participant of the Specific Groups in the Brief Exposure to the Training Phase of Experiment 4

\begin{tabular}{lllllll}
\hline Schedule & Participant & R/s & Participant & R/s & Participant & R/s \\
\cline { 2 - 7 } & \multicolumn{5}{c}{ Specific } \\
\cline { 2 - 7 } FR 15 & Self-rule & \multicolumn{7}{c}{ Rule } \\
VSR21 & 3.8 & VR21 & 5.5 & VC21 & 4.4 \\
FR 15 & VSR22 & 7.6 & VR22 & 5.6 & VC22 & 5.9 \\
FR 15 & VSR23 & 5.9 & VR23 & 4.4 & VC23 & 5.8 \\
FR 15 & VSR24 & 4.4 & VR24 & 5.5 & VC24 & 4.5 \\
\hline
\end{tabular}

\section{Testing}

Response-rate resistance obtained in the first five cycles of the testing phase for each participant in the specific groups is shown in Figure 5. Mean values are represented by the filled squares. The introduction of the FI schedule reduced response rates for most participants in all three groups. 
However, the reduction shown by participants in the SSR and SR groups was not as great as that obtained for participants in the VSR and VR groups in Experiments 1 and 2. Also, participants in the SSR and SR groups showed substantial responding across the testing phase, an effect not observed for participants in the VSR and VR groups in Experiments 1 and 2. The reduction in the response rates for participants of the SC group, on the other hand, was similar to that observed for the participants of the control groups in Experiments 1 and 2.

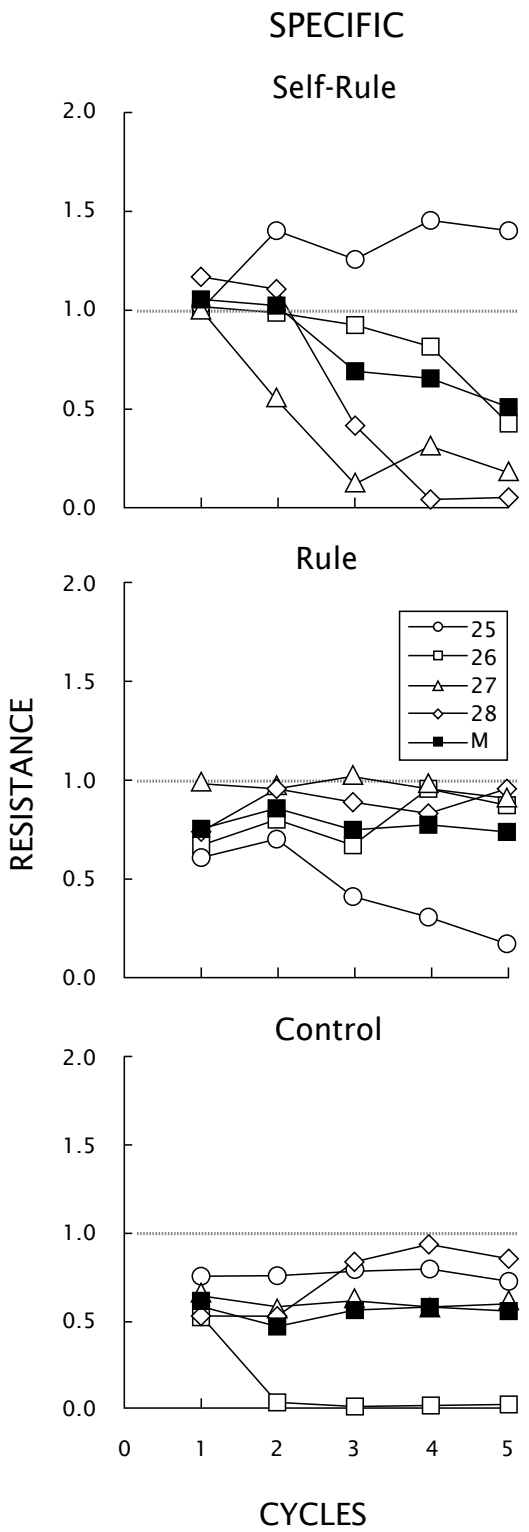

Figure 5. Resistance to schedule change, from FR to FI, for each participant in the specific groups in Experiment 4. Mean values are indicated by the filled squares. 
The results of Experiment 4 suggest that the number of reinforcers may not have been a critical variable in determining sensitivity to the FI schedule in the previous experiments. Nevertheless, because some participants showed high levels of sensitivity in the last cycles, the contribution of this variable to behavioral sensitivity in the present experiments cannot be ruled out. The absence of a clear effect of the number of reinforcers may be due to the schedule arrangement. It has been demonstrated that the direct relation between number of reinforcers and resistance to change is obtained consistently with multiple schedules but not with simple schedules (e.g., Cohen, Riley, \& Weigle, 1993), as was the case in the present study.

\section{GENERAL DISCUSSION}

The present findings provide further evidence that previous exposure to varied self-rules (and rules), as opposed to a single one, facilitates the development of control by new contingencies. This effect occurred regardless of whether verbal stimuli were self-generated or socially mediated (i.e., selfrules and rules, respectively) and regardless of whether self-rules were selected from a list of verbal stimuli (as with multiple-choice questions in Experiment 1) or not (as with open-ended questions in Experiment 2). This increased sensitivity was obtained as long as the exposure to varied self-rules and rules generated response-rate variability (Experiments 1-3), and independently of the number of reinforcers previously obtained (Experiment 4).

The results reported here expand the data provided by LeFrancois et al. (1988), given that they indicate that a history with varied schedules may promote sensitivity to contingency changes as long as (a) varied rules are also provided and (b) those schedules and rules engender response-rate differentiation. In particular, the present findings suggest that the role of rules on behavioral sensitivity is dependent upon behavioral variation: When there is response-rate differentiation, sensitivity is low, regardless of the presence of rules, but when such differentiation occurs, sensitivity is higher in the presence of rules.

Several studies suggest that a variable behavioral repertoire facilitates adaptation to new contingencies (e.g., Grunow \& Neuringer, 2002; Joyce \& Chase, 1990; Torgrud, Holborn, \& Zak, 2006; Wulfert et al., 1994). In the present study, for example, the programmed contingencies for the varied groups in Experiments 1 and 2 included fixed and variable schedules, response-dependent and response-independent reinforcers, and ratio and interval schedules. Those schedules generated high, intermediate, and low response rates. For the specific groups, on the other hand, only one schedule was in effect, and high response rates were observed throughout the training session. As a result, one may suggest that when the FI was implemented and high-rate responding was no longer the most efficient performance, participants in the varied groups would be in greater adaptive advantage compared to participants in the specific groups due to the larger number of behavioral alternatives in their repertoire.

It is likely that such adaptive advantage occurs because a variable behavioral pattern may contain an alternative that would be reinforced when a new contingency is implemented. This possibility was directly investigated by Torgrud et al. (2006, Experiment 1). In their study, participants were distributed into three groups during the training phase. Two variety groups 
were exposed to several schedules and accurate rules. For the functional variety group, those schedules and rules produced differentiated response rates. Some of those response rates were similar to the most efficient response rate in the testing phase. For the non-functional variety group, the programmed schedules also produced differentiated response rates, but the differential rates were very dissimilar to the one that would be appropriate in the testing phase. The third group, specific instruction, was exposed only to a VR schedule and to an accurate rule. In the testing phase, an FI schedule was in effect for all groups. This design permitted the researchers to evaluate two possible explanations for the increased sensitivity after a varied history with schedules and rules. One explanation is that a varied history generates behavioral patterns that overlap with the most efficient one under the testing condition. The other is that a varied history promotes the learning of an implicit rule: The contingencies are always changing; hence, when new contingencies are in place, behavior should change. The results obtained seem to favor the former explanation: The functional variety group was more likely to show an efficient response rate in the FI schedule than the remaining groups (see also Joyce \& Chase, 1990). Nevertheless, some aspects of the present study, as well as of the Torgrud et al. study, suggest that the second explanation should not be discarded. First, Torgrud et al. did not include a group with varied schedules but with no self-rules or rules. Second, the inclusion of such a group (varied control) in Experiments 1 and 2 of the present study indicated that differentiated response rates were not sufficient to generate behavioral sensitivity.

In fact, under the conditions provided by the present study, both explanations are plausible. It can be argued that the verbal stimuli not only interacted with response-rate variability but also strengthened the discriminability of the schedule changes. As a result, in the testing session, the schedule change evoked a change in behavior, and the presence of alternative behavioral patterns facilitated the selection of the most effective one under the new schedule (Joyce \& Chase, 1990; LeFrancois et al., 1988; Wulfert et al., 1994). When there was no rule, the discriminability of the changes in the schedules was reduced and lower sensitivity occurred. This account is consistent with Schlinger and Blakely's (1987) argument that rules should be conceptualized as function-altering stimuli (FAS).

Further, just as the behavior of the self-rules and rules participants in the varied groups may have been affected by an (implicit) "vary" rule, the behavior of the self-rules and rules participants in the specific groups may also have been influenced by an (also implicit) "repeat" rule. That is, the specific self-rules and rules may have not contributed to a faster acquisition under the testing schedule because those rules accentuated the unchanging characteristic of the experimental conditions. This effect, together with the restricted behavioral repertoire at the moment of change, may have prevented contact with the new schedule. This "repeat" rule also may have prevented control by the number of reinforcers, as was observed in Experiment 4.

The present results are consistent with those reported by Rosenfarb et al. (1992) in that self-rules and rules affected similarly the sensitivity to changing contingencies. Furthermore, the present findings provide an additional contribution: The similarity between rules and self-rules occurs whether self-rules are obtained by means of multiple-choice or open-ended questions. 
One difference between the results of Rosenfarb et al. (1992) and the present results must be highlighted. While varied self-rules and rules promoted behavioral insensitivity in their study, they generated sensitivity in the present study. This inconsistency may be due to the fact that in the study by Rosenfarb et al., the change from the multiple FR DRL schedule to extinction was not signaled, while in the present study, the change from the FR to the FI schedule was accompanied by a change in the discriminative stimulus (square color). This suggestion is supported by the findings reported by Hanna, Blackman, and Todorov (1992). These investigators found that response rates tend to remain unaltered when the discriminative stimuli do not change after a schedule change but not when there is a change in those stimuli (see also Freeman \& Lattal, 1992; Okouchi, 2003).

The present study has three main limitations. First, a group design with a small sample $(n=4)$ was employed, and one could argue that the generalization of the results may be somewhat compromised. Nevertheless, orderly data was obtained, and the main results were replicated across diverse experimental conditions. Additionally, the obtained effects corroborate previous studies (e.g., LeFrancois et al., 1988; Rosenfarb et al., 1992; Torgrud et al., 2006), which seems to strengthen the generalization of the conclusions.

Second, in some conditions (Experiments 2-4), participants of the self-rule groups did not present accurate self-rules during the training phase, and the effects of those inaccurate self-rules upon sensitivity to the FI schedule were not isolated. To help clarify the effects of those inaccurate rules, the responserate resistance of participants in the self-rule groups can be compared to the resistance presented by participants in the rule groups. By visually inspecting Figures 3 through 5, it can be observed that intragroup variability was higher for self-rule groups than for rule and control groups. This was true despite the fact that, in Experiment 2, inaccurate self-rules sometimes were given to the yoked rules participants of the varied and specific groups, whereas in Experiments 3 and 4, rule participants always received accurate rules. Although those inaccurate self-rules produced more variability at the individual level, the means of the self-rule and rule groups showed trends that were similar and consistent with the predictions. The evaluation of the effects of inaccurate selfrules and rules upon behavioral sensitivity was beyond the scope of the present study, but it seems important that future studies address this question.

Finally, each schedule in the present experiment was correlated with a different color. It is possible that schedule-correlated stimuli (e.g., Takahashi \& Iwamoto, 1986) may have interacted with rules and schedules in affecting behavioral sensitivity (for further considerations, see also Freeman \& Lattal, 1992; Hanna, Blackman, \& Todorov, 1992; Okouchi, 2003).

\section{REFERENCES}

ALBUQUERQUE, L. C., \& FERREIRA, K. V. D. (2001). Efeitos de regras com diferentes extensões sobre o comportamento humano. [Effects of rule size on human behavior]. Psicologia: Reflexão e Crítica, 14, 143-155.

AYLLON, T., \& AZRIN, N. H. (1964). Reinforcement and instructions with mental patients. Journal of the Experimental Analysis of Behavior, 7, 327-331.

BARRETT, D. H., DEITZ, S. M., GAYDOS, G. R., \& QUINN, P. C. (1987). The effects of programmed contingencies and social conditions on response stereotypy with human subjects. The Psychological Record, 37, 489-505. 
BARON, A., KAUFMAN, A., \& STAUBER, K. A. (1969). Effects of instructions and reinforcement-feedback on human operant behavior maintained by fixed-interval reinforcement. Journal of the Experimental Analysis of Behavior, 12, 701-712.

CABELLO, F., LUCIANO, C., GOMEZ, I., \& BARNES-HOLMES, D. (2004). Human schedule performance, protocol analysis and the "silent dog" methodology. The Psychological Record, 54, 405-422.

CERUTTI, D. T. (1991). Discriminative versus reinforcing properties of schedules as determinants of schedule insensitivity in humans. The Psychological Record, 41, 51-67.

COHEN, S. L., RILEY, D. S., \& WEIGLE, P. A. (1993). Tests of behavior momentum in simple and multiple schedules with rats and pigeons. Journal of the Experimental Analysis of Behavior, 60, 255-291.

DANFORTH, J. S., CHASE, P. N., DOLAN, M., \& JOYCE, J. H. (1990). The establishment of stimulus control by instructions and by differential reinforcement. Journal of the Experimental Analysis of Behavior, 54, 97-112.

FREEMAN, T. J., \& LATTAL, A. K. (1992). Stimulus control of behavioral history. Journal of the Experimental Analysis of Behavior, 57, 5-15.

GALIZIO, M. (1979). Contingency-shaped and rule-governed behavior: Instructional control of human loss avoidance. Journal of the Experimental Analysis of Behavior, 31, 53-70.

GRACE, R. C., MCLEAN, A. P., \& NEVIN, J. A. (2003). Reinforcement context and resistance to change. Behavioural Processes, 64, 91-101.

GRACE, R. C., SCHWENDIMAN, J. W., \& NEVIN, J. A. (1998). Effects of unsignaled delay of reinforcement on preference and resistance to change. Journal of the Experimental Analysis of Behavior, 69, 247-261.

GRUNOW, A., \& NEURINGER, A. (2002). Learning to vary and varying to learn. Psychonomic Bulletin \& Review, 9, 250-258.

HACKENBERG, T. D., \& JOKER, V. R. (1994). Instructional versus schedule control of humans' choices in situations of diminishing returns. Journal of the Experimental Analysis of Behavior, 62, 367-383.

HANNA, E. S., BLACKMAN, D. E., \& TODOROV, J. C. (1992). Stimulus effects on concurrent performance in transition. Journal of the Experimental Analysis of Behavior, 58, 335-347.

HAYES, S. C., BROWNSTEIN, A. J., ZETTLE, R. D., ROSENFARB, I., \& KORN, Z. (1986). Rule-governed behavior and sensitivity to changing consequences of responding. Journal of the Experimental Analysis of Behavior, 45, 237-256.

JOYCE, J. H., \& CHASE, P. N. (1990). Effects of response variability on the sensitivity of rule-governed behavior. Journal of the Experimental Analysis of Behavior, 54, 251-262.

KAUFMAN, A., BARON, A., \& KOPP, R. E. (1966). Some effects of instructions on human operant behavior. Psychonomic Monograph Supplements, 11, 243-250.

LEFRANCOIS, J. R., CHASE, P. N., \& JOYCE, J. H. (1988). The effects of a variety of instructions on human fixed-interval performance. Journal of the Experimental Analysis of Behavior, 49, 383-393.

MADDEN, G. J., CHASE, P. N., \& JOYCE, J. H. (1998). Making sense of sensitivity in the human operant literature. The Behavior Analyst, 21, $1-12$. 
MARTINEZ-SANCHEZ, H., \& RIBES-IÑESTA, E. (1996). Interactions of contingencies and instructional history on conditional discrimination. The Psychological Record, 46, 301-307.

MATTHEWS, B. A., CATANIA, A. C., \& SHIMOFF, E. (1985). Effects of uninstructed verbal behavior on nonverbal responding: Contingency descriptions versus performance descriptions. Journal of the Experimental Analysis of Behavior, 43, 155-164.

NAVARICK, D. J. (2004). Analysis of impulsive choice: Assessing effects of implicit instructions. The Psychological Record, 54, 505-522.

NEVIN, J. A. (1974). Response strength in multiple schedules. Journal of the Experimental Analysis of Behavior, 21, 389-408.

NEVIN, J. A. (2002). Measuring behavioral momentum. Behavioural Processes, 57, 187-198.

NEWMAN, B., HEMMES, N. S., BUFFINGTON, D. M., \& ANDREOPOULOS, S. (1994). The effects of schedules of reinforcement on instruction following in human subjects with verbal and nonverbal stimuli. The Analysis of Verbal Behavior, 12, 31-41.

OKOUCHI, H. (2003). Stimulus generalization of behavioral history. Journal of the Experimental Analysis of Behavior, 80, 173-186.

OTTO, T. L., TORGRUD, L. J., \& HOLBORN, S. W. (1999). An operant blocking interpretation of instructed insensitivity to schedule contingencies. The Psychological Record, 49, 663-684.

PARACAMPO, C. C. P., SOUZA, D. G., MATOS, M. A., \& ALBUQUERQUE, L. C. (2001). Efeitos de mudanças em contingências de reforço sobre o comportamento verbal e não verbal. [Effects on verbal and nonverbal behavior of changes in reinforcement contingencies]. Acta Comportamentalia, 9, 31-55.

RAIA, C. P., SHILLINGFORD, S. W., MILLER, H. L., JR., \& BAIER, P. S. (2000). Interaction of procedural factors in human performance on yoked schedules. Journal of the Experimental Analysis of Behavior, 74, 265-281.

ROSENFARB, I. S., NEWLAND, M. C., BRANNON, S. E., \& HOWEY, D. S. (1992). Effects of self-generated rules on the development of schedulecontrolled behavior. Journal of the Experimental Analysis of Behavior, 58, 107-121.

SCHLINGER, H., \& BLAKELY, E. (1987). Function-altering effects of contingency-specifying stimuli. The Behaviour Analyst, 10, 41-45.

SHIMOFF, E., CATANIA, A. C., \& MATTHEWS, B. A. (1981). Uninstructed human responding: Sensitivity of low-rate performance to schedule contingencies. Journal of the Experimental Analysis of Behavior, 36, 207-220.

SKINNER, B. F. (1969). Contingencies of reinforcement: a theoretical analysis. New York: Appleton-Century-Crofts.

TAKAHASHI, M., \& IWAMOTO, T. (1986). Human concurrent performances: The effects of experience, instructions, and scheduled-correlated stimuli. Journal of the Experimental Analysis of Behavior, 45, 257-267.

TAKAHASHI, M., \& SHIMAKURA, T. (1998). The effects of instructions on human matching. The Psychological Record, 48, 171-181.

TORGRUD, L. J., \& HOLBORN, S. W. (1990). The effects of verbal performance descriptions on nonverbal operant responding. Journal of the Experimental Analysis of Behavior, 54, 273-291. 
TORGRUD, L. J., HOLBORN, S. W., \& ZAK, R. D. (2006). Determinants of human fixed-interval performance following varied exposure to reinforcement schedules. The Psychological Record., 56, 105-133.

WULFERT, E., GREENWAY, D. E., FARKAS, P., HAYES, S. C., \& DOUGHER, M. J. (1994). Correlation between self-reported rigidity and rule-governed insensitivity to operant contingencies. Journal of Applied Behavior Analysis, 27, 659-671. 